\title{
A low-cost apparatus for transforming Drosophila and detecting green fluorescent protein (GFP) genetic markers
}

\author{
Maríndia Deprá ${ }^{1}$, Lenira Maria Nunes Sepel ${ }^{2}$ and Élgion Lucio da Silva Loreto ${ }^{2}$ \\ ${ }^{1}$ Universidade Federal do Rio Grande do Sul, PPG Genética e Biologia Molecular, \\ Porto Alegre, RS, Brazil. \\ ${ }^{2}$ Universidade Federal de Santa Maria, Departamento de Biologia, Santa Maria, RS, Brazil.
}

\begin{abstract}
We describe the transformation of white mutant Drosophila simulans with a piggyBac transposon vector and a green fluorescent marker (GFP) and show how to construct inexpensive micro-manipulation and epifluorescence equipment for use in transposon-mediated germ-line transformation. Although the number of $G_{0}$ adult flies (16) obtained in relation to the number of injected eggs was very low (12.5\%) it was comparable to the proportion described by other authors and can be considered as a good rate of transformation.
\end{abstract}

Key words: transgenic Drosophila, piggyBac, GFP, transposable elements.

Received: April 24, 2003; Accepted: October 12, 2003

\section{Introduction}

Transposon-mediated germ-line transformations have been the approach most extensively used to obtain transgenic insects and other animals (Handler, 2001). In this approach a DNA transposon is used in a binary vector/helper system that allows the precise and stable insertion of any desirable DNA sequence into the target genome. Although $P$-element transformation has been a routine technique for Drosophila researchers for more than twenty years (Rubin and Spradling, 1982), transposon-mediated germ-line transformations were restricted to this model organism because the $P$ transposon is inactive in nondrosophilids (Rio and Rubin, 1988). More recently, this methodology has been extended to other insects (Klinakis et al., 2000; Handler, 2001), fish (Fadool et al., 1998) and chickens (Shermann et al., 1998) due to the use of vectors containing various other transposons (e.g. mariner, hermes, minos and piggyBac) which are functional in a wide range of animals and require no additional cofactors for mobilization (Horn and Wimmer, 2000).

Until a few years ago, another obstacle to the use of transposon-mediated germ-line transformation was the difficulty in obtaining marker genes that permit easier and more reliable identification of transgenic animals. In general, a species-specific transformation marker can be generated by isolating visible mutations in the species of interest, cloning the corresponding gene and rescuing the mutant phenotype by the incorporation of a wild copy of this gene by transformation. However, this process is very laborious

Send correspondence to Élgion L.S. Loreto. E-mail: elgion@base. ufsm.br. for many species and often delays the development of new procedures. A universal marker that can be used to show gene transfer in any species is the green fluorescent protein (GFP) under the control of artificial promoters, this marker now being widely used in various species (Berghammer et al., 1999; Horn and Wimmer, 2000; Horn et al., 2000; 2002).

An additional restriction to the wide use of transposon-mediated germ-line transformation is the need for a micro-manipulator, micro-needles, micro-injection systems and, when the GFP marker is employed, a stereomicroscope equipped for epifluorescence. In this note we describe the transformation of Drosophila simulans with a GFP marker and show how to construct inexpensive micro-manipulation and epifluorescence equipment.

\section{Material and Methods}

\section{Flies and the preparation of embryos}

The white mutant strain (Torres, 2001) of Drosophila simulans was used as recipient for the marker. About 200 adult flies were transferred to a $300 \mathrm{~mL}$ empty bottle which was inverted over a petri dish containing banana medium consisting of $20 \%(\mathrm{w} / \mathrm{v})$ banana, $1.5 \%(\mathrm{w} / \mathrm{v})$ agar and sufficient food coloring to facilitate picking up of the eggs. After $30 \mathrm{~min}$ this first plate was removed and discarded because many of the embryos were old and partially developed at the time of laying, the bottle being placed on a second plate of the same medium for a further $30 \mathrm{~min}$ to allow the flies to deposit fresh embryos. Fine-tipped forceps were used to dechorionated the embryos by rolling them on double-sided 
adhesive tape before transferring them to a slide where they were lightly fixed onto double-sided adhesive tape and desiccated over $\mathrm{CaCl}_{2}$ for 2-5 min. To protect the eggs being from complete desiccation we covered them with halocarbon oil 700 (Sigma), Nujol mineral oil (liquid paraffin oil, available locally from pharmacies) also being tested as a cheaper alternative to halocarbon oil. After desiccation, the slide and embryos were transferred to a microscope for micro-injection by the method of Fujioka et al. (2000).

\section{Plasmids}

We used the pBac [3xp3-EGFPafm] (Horn and Wimmer, 2000) plasmid, containing the piggyBac transposon inverted terminal repeats (ITRs) and the GFP gene marker under the control of an artificial promoter containing three Pax-6 homo-dimer binding sites. This promoter drives strong expression of the GFP protein in the eye-tissues of larva, pupa and adult flies. The piggyBac transposase helper-plasmid used was the $\mathrm{pB} \Delta \mathrm{Sac}$ helper-plasmid with its 5 ' terminus deleted (Handler and Harrell, 1999).

Another plasmid set was used to investigate possible GFP toxicity in $D$. simulans, this set consisting of a $P$ ele- ment pCASPER construct, containing the mini-white gene along with the $\mathrm{p} \pi 25.5$ plasmid containing the $P$ element transposase gene (Karess and Rubin, 1984). All the plasmids were prepared using the PEG protocol (Fujioka et al., 2000).

\section{Injection procedure}

To inject the DNA the embryos were lined up on slides and a micro-manipulator used to place a needle precisely at the posterior of the embryo. During injection, embryos need to be pushed against the needle, and it is better to do this by moving the microscope stage rather than the micro-manipulator controls. Since not all laboratories have access to a micro-manipulator we designed a micromanipulation apparatus that uses the mechanical stage control of an old microscope. In our apparatus the stage verniers, control screws, slide holder and retaining clip are fixed onto a plate attached to a Leitz stereo-microscope lampsupport in such a way that the plate can move vertically and horizontally, this plate serving as a support for the embryo-injection needle (Figure 1).
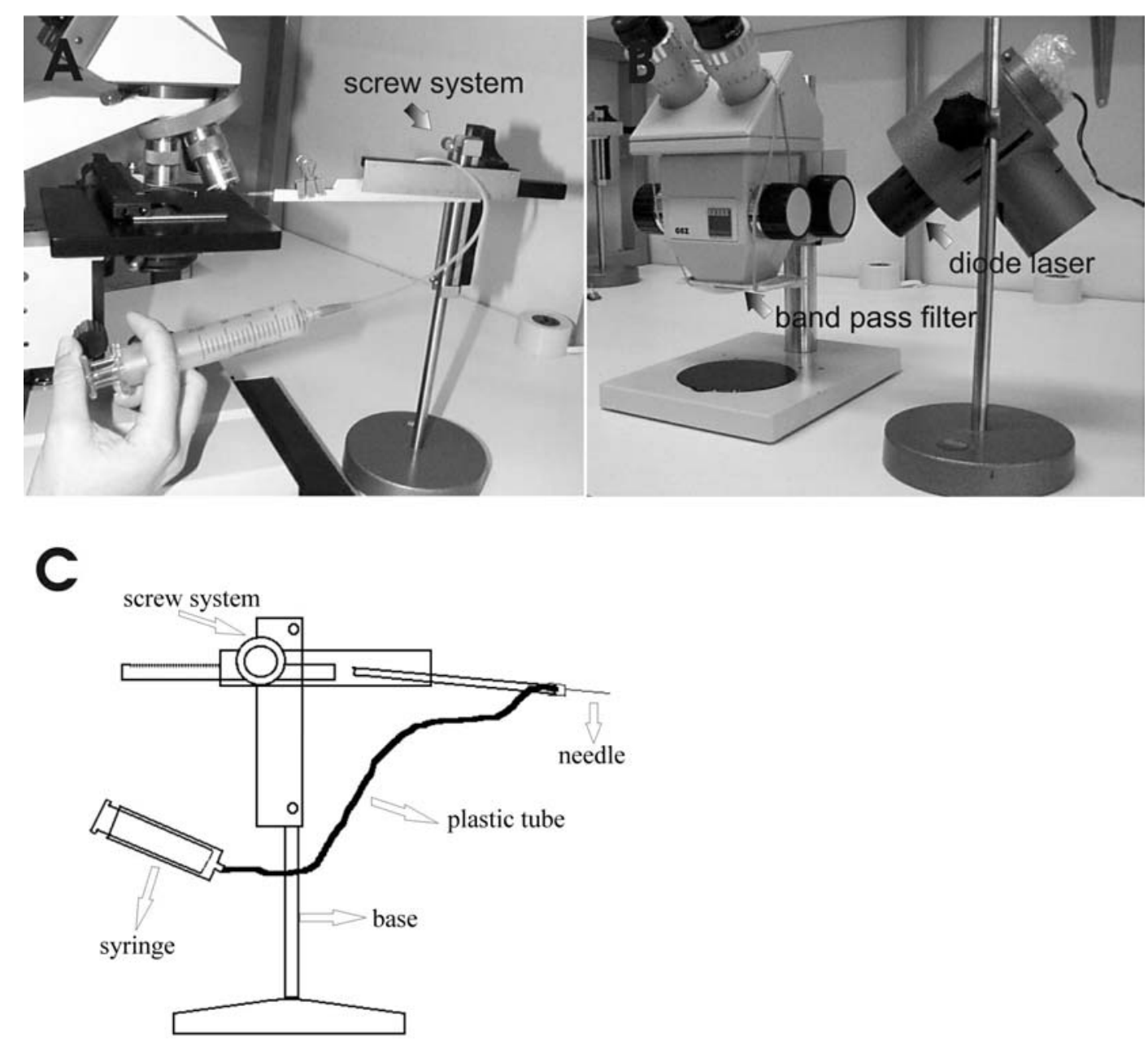

Figure 1 - A: Micro-manipulation apparatus based on a mechanical microscope stage. B: Stereo-microscope with a band-pass filter added to the objective lens and a laser diode. C: Diagram of the main parts of the micro-manipulation apparatus. 
We tested several different micro-injection systems employing micropipettes and syringes of various volumes attached to polyethylene tubes filled with paraffin oil, water or air and found that the simplest and most efficient system consisted of a $20 \mathrm{~mL}$ glass syringe attached to an intravenous injection 'butterfly' tube with a yellow micro-pipette tip glued to its free end to serve as a needle-holder (Figure 1). Needles were made from $0.2 \mathrm{~mm}$ internal diameter capillary tubes (Hyalo-technique laboratory, Chemistry Department, Federal University of Santa Maria, Santa Maria-RS, Brazil) by hand-pulling these capillaries over the flame of an alcohol lamp to produce capillaries so thin that they were invisible to the naked eye, a microscope being used to visualize the capillaries in order to break them with a shape scalpel and form fine needle-ends. The finest needles were glued with cyanoacrylic instant adhesive (SuperBonder®) onto a $10 \mu \mathrm{L}$ micro-pipette tip, this arrangement allowing faster and easier needle replacement.

This apparatus was used to inject the embryos with ultra-pure water to which had been added $200 \mathrm{ng} / \mu \mathrm{L}$ of each vector and helper plasmid.

\section{Epifluorescence microscopy}

The excitation wavelength of GFP is between $480 \pm 40 \mathrm{~nm}$, detection of GFP normally requiring a microscope fitted with expensive high-voltage epifluorescence equipment. In our experiments we tested two different light sources, one consisting of inexpensive violet light-emitting diodes (LEDs, obtainable from electronic component stores) fed with a cheap power supply (Dove, 2002) and the other made from laser diodes $(405 \mathrm{~nm}, 5 \mathrm{~mW}$ maximum output). For both systems we used a $510 \mathrm{~nm}$ emission band-pass filter attached to the objective lens of a Zeiss stereo-microscope (Figure 1-B). The observations were done in a darkroom with the operator wearing UV-blocking safety glasses.

\section{Results and Discussion}

Our results show that it was indeed possible to transform flies with GFP using the low-cost micro-injection and epifluorescence equipment described above. Although the number of adult flies obtained in relation to the number of injected eggs was low (Table1), it was comparable to the proportion previously described by Horn et al. (2000 and 2002).

Transformation frequency is normally reported as the percentage of transformed flies in relation to fertile adults in the $\mathrm{G}_{0}$ generation. Working with various insects, Handler (2002) reported piggyBac transformation frequencies ranging from about $1-2 \%$ to more than $40 \%$ for fertile $G_{0}$ members. We found two transformed flies out of a total of $16 \mathrm{G}_{0}$ adult flies (12.5\%), which can be considered a good rate of transformation.

Felts et al. (2000) and Handler (2002) reported that GFP expression can be toxic to some insects, which may account for the low production of larvae and $\mathrm{G}_{0}$ flies with the GFP construct as compared to larvae and $\mathrm{G}_{0}$ flies containing the mini-white plasmid construct (Table 1).

Transformed flies were not obtained with the pCASPER construct (a $P$ element combined with a miniwhite gene), which may have been due to the fact that only a few eggs were injected with this combination and that the $P$ element is not so efficient at transforming $D$. simulans (Kimura and Kidwell 1994).

Although mineral oil is cheaper and easier to obtain, halocarbon oil appeared to be more effective than mineral oil at protecting eggs from desiccation, in one case six times more larvae being obtained using halocarbon oil (Table 1).

Although LEDs permitted separation of transformed flies from untransformed flies the quality of the images was not as high as when laser diodes were used, laser diodes being highly efficient at producing good visualization of fluorescent eyes (Figure 2) and justifying the extra cost involved in purchasing these diodes.

In the near future more and more transposonmediated germ-line transformations will be used to obtain transgenic insects and other animals for both academic and applied research. In this note we have described some procedures that permit laboratories that do not have the resources to buy commercial micro-manipulators and epifluorescence equipment to use transposon-mediated germ-line transformation technology in their research programs.

Table 1 - Number and frequency of injected eggs and other developmental stages of Drosophila simulans injected with piggyBac and $P$ element plasmids.

\begin{tabular}{|c|c|c|c|c|c|c|}
\hline \multirow[t]{3}{*}{ Drosophila simulans } & \multirow{2}{*}{\multicolumn{2}{|c|}{$\frac{\text { PiggyBac - GFP plasmids }}{\text { Halocarbon oil }}$}} & \multicolumn{4}{|c|}{$P$ element - white plasmids } \\
\hline & & & \multicolumn{2}{|c|}{ Halocarbon oil } & \multicolumn{2}{|c|}{ Mineral oil } \\
\hline & Number & $\%$ & Number & $\%$ & Number & $\%$ \\
\hline Injected eggs & 1680 & 100 & 30 & 100 & 126 & 100 \\
\hline Larvae & 36 & 2.14 & 12 & 40 & 9 & 7.14 \\
\hline Pupae & 31 & 1.85 & 9 & 30 & 2 & 1.59 \\
\hline $\mathrm{G}_{0}$ adult flies & 16 & 0.95 & 4 & 13.3 & 2 & 1.59 \\
\hline Transformed adult flies & 2 & 0.12 & 0 & - & 0 & - \\
\hline
\end{tabular}



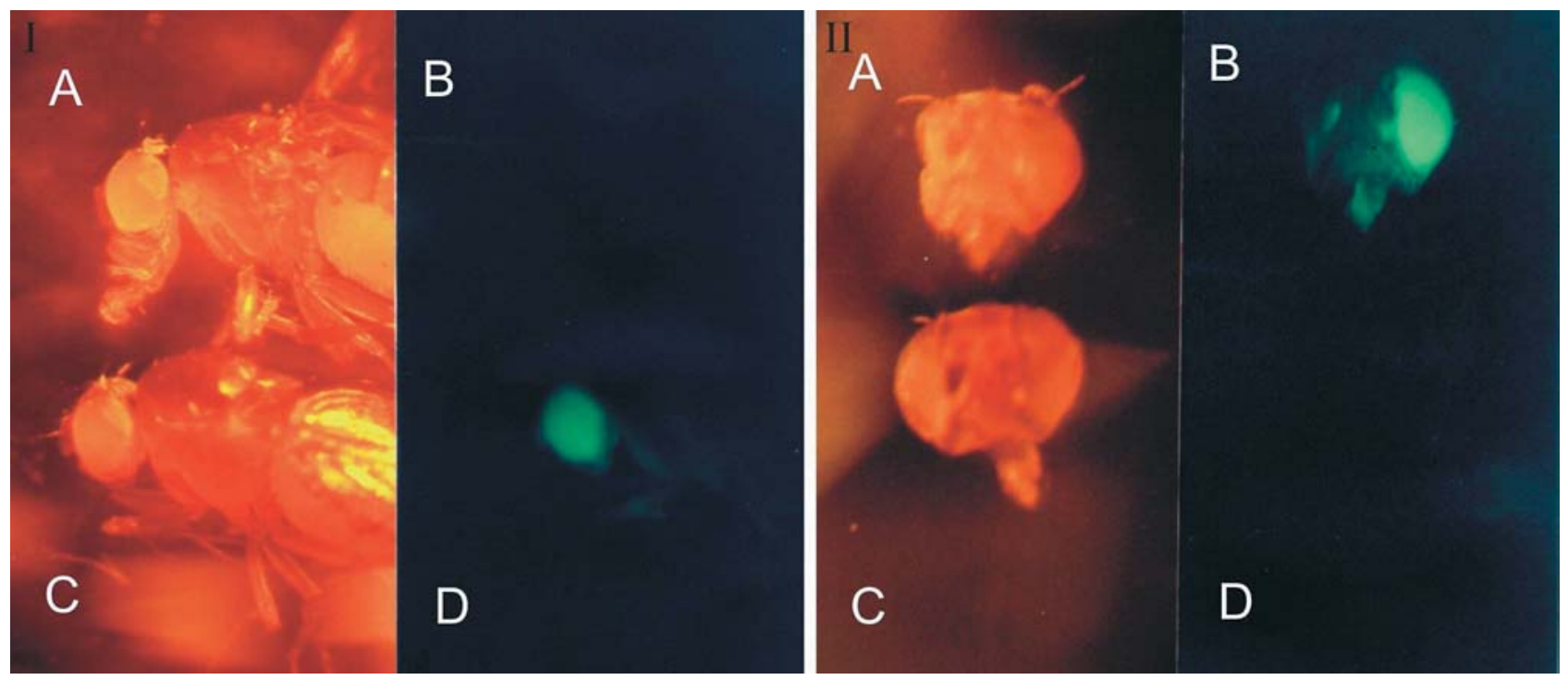

Figure 2 - Stereo-photomicrographs of Drosophila simulans. In the first part of the figure (I) the top fly (A and B) is untransformed and the bottom fly (C and D) is piggyBac GFP transformed. In the second part of the figure (II) the top fly is transformed and the bottom fly is a control. Columns A and C show flies illuminated with white light while columns B and D show flies illuminated with UV light.

\section{Acknowledgments}

This work was supported by grants from FAPERGS (numbers 01/0927.4 and 00513957) and FIPE-UFSM (number 10100). We thank ISBiothec Ltda (Porto Alegre, RS) for providing laser diodes and filters, Dr.Tarso Kist (Department of Biophisics -UFRGS) for help regarding the fluorescence detection systems, Dr. Neri Paniz (Hyalotechnique laboratory, UFSM) for providing the capillaries. The $p B a c$ plasmid and $p B \Delta S a c$ helper-plasmid were kindly provided by Dr. Ernest Wimmer (Universität Bayreuth, Germany).

\section{References}

Berghammer AJ, Klingler M and Wimmer EA (1999) A universal marker for transgenic insects. Nature 402:370-371.

Dove, A (2002) Fluorescence Microscopy on a microbudget. The Scientist 16:47-48.

Fadool JM, Hartl DL and Dowling JE (1998) Transposition of the mariner element from Drosophila mauritiana in zebrafish. Proc Natl Acad Sci USA 95:5182-5186.

Felts K, Rogers B, Chen K, JI H, Sorge J and Vaillancourt P (2000) Recombinant Renilla reniformis GFP displays low toxicity. Strategies 13:85-87.

Fujioka M, Jaynes JB, Bejsovec A and Weir M (2000) Production of transgenic Drosophila. Methods in Molecular Biology 136:353-363.

Handler AM (2002) Use of the piggyBac transposon for germ-line transformation of insects. Insect Biochem Mol Biol 32:1211-1220.

Handler AM (2001) A current perspective on insect gene transformation. Insect Biochem Mol Biol 31:111-128.
Handler AM and Harrell RA (1999) Germline transformation of Drosophila melanogaster with the piggyBac transposon vector. Insect Mol Biol 8:449-457.

Horn C, Jaunich B and Wimmer EA (2000) Highly sensitive, fluorescent transformation marker for Drosophila transgenesis. Dev Genes Evol 210:623-629.

Horn C and Wimmer EA (2000) A versatile vector set for animal transgenesis. Dev Genes Evol 210:630-637.

Horn C, Bernhard GM, Schmid FS and Wimmer EA (2002) Fluorescent transformation markers for insect transgenesis. Insect Biochem Mol Biol 32:1221-1235.

Karess RE and Rubin GM (1984) Analysis of $P$ transposable element functions in Drosophila. Cell 38:135-46.

Kimura K and Kidwell MG (1994) Differences in $P$ element population dynamics between the sibling species Drosophila melanogaster and Drosophila simulans. Genet Res 63:2738.

Klinakis AG, Loukeris TG, Pavlopoulos A and Savakis C (2000) Mobility assays confirm the broad host-range activity of the Minos transposable element and validate new transformation tools. Insect Mol Biol 9:269-275.

Rio DC and Rubin GM (1988) Identification and purification of a Drosophila protein that binds to the terminal 31-base-pair inverted repeats of the $P$ transposable element. Proc Natl Acad Sci USA 85:8929-33.

Rubin GM and Spradling AC (1982) Genetic transformation of Drosophila with transposable element vectors. Science 218:348-353.

Sherman A, Dawson A, Mather C and Finnegan D (1998) Transposition of the Drosophila element mariner into the chicken germ-line. Nature Biotech 16:1050-1053.

Torres FP (2001) Caracterização molecular de um mutante white de Drosophila simulans. Dissertação de mestrado, PPG Genética e Biologia Molecular UFRGS, Porto Alegre.

Editor: Louis Bernard Claczko 